\title{
The Memory Alteration Test Discriminates between Cognitively Healthy Status, Mild Cognitive Impairment and Alzheimer's Disease
}

\begin{abstract}
Nilton Custodio a, b, d David Lira a, b, d Eder Herrera-Perez ${ }^{d-f}$
Liza Nuñez del Pradod, $g$ José Parodi ${ }^{\text {h }}$ Erik Guevara-Silva ${ }^{i}$

Sheila Castro-Suarez ${ }^{d, j}$ Rosa Montesinos ${ }^{b-d}$ Patricia Cortijo ${ }^{d}$

a Servicio de Neurología, bunidad de Diagnóstico de Deterioro Cognitivo y Prevención de Demencia, and 'Servicio de Medicina Física y Rehabilitación, Clínica Internacional, ¿Unidad de Investigación, Instituto Peruano de Neurociencias, eUnidad de Diseño y Elaboración de Proyectos de Investigación, ${ }^{f}$ Centro de Investigación para el Desarrollo Integral y Sostenible, Universidad Peruana Cayetano Heredia, ${ }^{9}$ Servicio de Neurología,

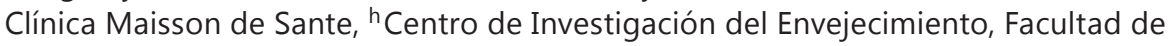
Medicina Humana, Universidad San Martín de Porres, 'Departamento de Medicina, Hospital de Chancay, and 'Servicio de Neurología de la Conducta, Instituto Nacional de Ciencias Neurológicas, Lima, Peru
\end{abstract}

\section{Key Words}

Dementia - Differential diagnosis - Memory alteration test

\section{Abstract}

Background/Aims: Dementia is a worldwide public health problem and there are several diagnostic tools for its assessment. The aim of this study was to evaluate the performance of the Memory Alteration Test (M@T) to discriminate between patients with early Alzheimer's disease (AD), patients with amnestic mild cognitive impairment (a-MCI), and subjects with a cognitively healthy status (CHS). Methods: The discriminative validity was assessed in a sample of 90 patients with $A D, 45$ patients with a-MCI, and 180 subjects with CHS. Clinical, functional, and cognitive studies were independently performed in a blinded fashion and the gold standard diagnosis was established by consensus on the basis of these results. The test performance was assessed by means of a receiver operating characteristic curve analysis as area under the curve (AUC). Results: M@T mean scores were $17.7(S D=5.7)$ in $A D, 30.8(S D=2.3)$ in a-MCI, and $44.5(\mathrm{SD}=3.1)$ in CHS. A cutoff score of 37 points had a sensitivity of $98.3 \%$ and a specificity of $97.8 \%$ to differentiate a-MCI from CHS (AUC $=0.999$ ). A cutoff score of 27 points had a sensitivity of $100 \%$ and a specificity of $98.9 \%$ to differentiate mild AD from a-MCI and from CHS (AUC = 1.000). Conclusions: The M@T had a high performance in the discrimination between early $A D$, a-MCI and CHS. 


\section{Introduction}

Dementia is a worldwide public health problem. In Latin America, the prevalence of dementia in people older than 60 years is about 8.5\% [1-7]. Alzheimer's disease (AD) is the main cause of dementia around the world.

Mild cognitive impairment (MCI) occurs in nearly $9 \%$ of community-dwelling elderly in Latin American countries [8, 9]. Amnestic MCI (a-MCI) is a clinical entity recognized as a risk factor for $\mathrm{AD}[10]$, with a conversion rate to dementia of $4-25 \%$ per year [10-12], and represents a transition stage between normal cognition and mild AD $[13,14]$. Thus, a-MCI could be an $\mathrm{AD}$ precursor.

Currently, there are several diagnostic tools for assessing dementia [15-23], but the sensitivity for the early detection of dementia is very low [24]. Furthermore, the majority of tests are complex and need highly trained personnel and specialized equipment [25], which is not usually available at primary care level. Because of this, a-MCI and mild AD are often unrecognized in primary care centers [25]. Therefore, there is a need to develop a memory screening test oriented to the general practitioners that allows them to differentiate a-MCI and mild $\mathrm{AD}$ patients from normal cognitive controls, and that is easily applicable in daily practice in primary care centers.

The Memory Alteration Test (M@T), which is a brief and simple memory screening test, could be performed at primary care level. It has shown a good diagnostic performance in other studies. Thus, it arises as a promising alternative for the detection of early cognitive impairment by general practitioners [26].

The aim of this study was to assess the validity of the M@T for discriminating between subjects with a cognitively healthy status (CHS) and patients with a-MCI and mild AD.

\section{Materials and Methods}

\section{Design of the Study}

This study assesses the performance of the M@T as a diagnostic test. As a gold standard, consensus diagnosis by a neurologist and a neuropsychologist was used. Both the M@T and the gold standard were systematically and independently assessed in all consecutive eligible patients.

\section{Population and Sample}

All participants gave their informed consent. We included patients older than 60 years, with Spanish as their native language, with at least 6 years of education, who were consecutively enrolled during the period between April 2010 and December 2012. We excluded those subjects with structural and/or functional deficits (visual or auditory deficits), since they affect the performance of the cognitive tests, subjects with a history of diseases associated with secondary cognitive impairment [e.g. cerebrovascular diseases, hypothyroidism, infections of the central nervous system (HIV or syphilis), severe encephalic traumatism, and subdural hematoma], subjects with a history of conditions associated with secondary cognitive impairment (e.g. $B_{12}$ vitamin deficiency, chronic hepatopathy or nephropathy, and addiction or abuse of substances), as well as subjects with a score $>4$ on the Hachinski scale (which suggests an underlying cerebrovascular deficit).

This study included three groups: a-MCI, AD, and CHS. The a-MCI and AD groups were formed using the diagnostic criteria by Petersen et al. [27] and NINCDS-ADRDA [28], respectively. In the AD group, we only included patients with early and moderate dementia according to the Global Deterioration Scale (GDS-4 and GDS-5, respectively). The CHS group consisted 
Custodio et al.: The Memory Alteration Test Discriminates between Cognitively Healthy Status, Mild Cognitive Impairment and Alzheimer's Disease

of patients without memory complaints, and none of these patients met the diagnostic criteria for a-MCI or $\mathrm{AD}$ based on a clinical interview and neuropsychological testing including memory, language, and executive functions.

MCI is defined by Petersen et al. [11] as impairment of at least one cognitive function, normal activities of daily living and absence of dementia. This diagnostic entity can be divided into nonamnestic MCI and a-MCI [10], which is characterized by memory complaints (usually confirmed by an informant), objective memory impairment adjusted for age and education, and preserved general cognitive function [27].

Participants for the a-MCI and AD groups were enrolled among the patients who visited the neurology consulting room in the 'Clínica Internacional'. Participants for the CHS group were enrolled among the patients who visited the internal medicine (in the 'Clínica Internacional' or 'hospital militar central') or the preventive medicine consulting room (in the 'Clínica Internacional').

\section{Procedures}

All patients were evaluated using the same tests: the Mini Mental State Examination (MMSE) [15], the Pfeffer Functional Activities Questionnaire [29], and a standardized neuropsychological assessment battery [30] including tests for delayed recall, immediate recall, intrusion errors, and recognition memory. The GDS was administered only to patients with a diagnosis of AD.

\section{Memory Alteration Test}

The M@T is a screening test with high discriminative properties for a-MCI and early AD among the general primary care population aged $\geq 60$ years [26]. The maximum score on the $\mathrm{M} @ \mathrm{~T}$ is 50 . One point is given for each correct answer and there are a maximum and minimum of 50 and 40 questions, respectively, depending on the subject's success in free recall. All questions are oral and have only one possible answer. There are 5 subtests: encoding ( 5 points), orientation (10 points), semantic (15 points), free recall (10 points) and cued recall (10 points) [26].

\section{Statistical Analysis}

The discriminative validity of the $\mathrm{M} @ \mathrm{~T}$ was assessed by calculating the sensitivity and specificity of the M@T for discriminating a-MCI and early AD from CHS subjects.

The $\chi^{2}$ and Mann-Whitney tests for pairs of groups (a-MCI vs. CHS and AD vs. CHS) were used to compare demographic and neuropsychological scores between the groups. The influence of demographic variables on the association between diagnosis and M@T was studied by logistic regression analysis.

Receiver operating characteristic (ROC) curves were used in order to calculate the sensitivity and specificity of the M@T and MMSE. As both the M@T and MMSE are continuous variables, we sought to assess their diagnostic performance for different threshold values. For this, we estimated the area under the curve (AUC) for the ROC curves for the M @ T (global and by subtests) and MMSE. The cutoff points for sensitivity and specificity were based on the highest diagnostic accuracy (proportion of correct diagnoses). All analyses were performed by using STATA 12.0 (Stata Corporation, College Station, Tex., USA).

\section{Ethical Aspects}

This study was authorized by the Investigation and Teaching Unit of the 'Clínica Internacional'. The present study was approved by the Ethics Committee of the 'Universidad Privada San Martin de Porres'. 
Table 1. Demographic characteristics and test scores in 315 subjects attended at the neurology consulting room of the 'Clínica Internacional'

\begin{tabular}{|c|c|c|c|c|c|}
\hline & \multicolumn{3}{|l|}{ Groups } & \multirow{2}{*}{$\begin{array}{l}\mathrm{p} \text { value } \\
\text { (AD vs. } \\
\mathrm{MCI} \text { ) }\end{array}$} & \multirow{2}{*}{$\begin{array}{l}\text { p value } \\
\text { (MCI vs. } \\
\text { CHS) }\end{array}$} \\
\hline & $\begin{array}{l}A D \\
(n=90)\end{array}$ & $\begin{array}{l}\text { MCI } \\
(n=45)\end{array}$ & $\begin{array}{l}\text { CHS } \\
(n=180)\end{array}$ & & \\
\hline Female, n (\%) & $58(64.44)$ & $30(66.67)$ & $113(62.78)$ & $0.798^{*}$ & $0.628^{*}$ \\
\hline Age, years & $74.16 \pm 3.73$ & $71.09 \pm 4.20$ & $69.97 \pm 4.04$ & $0.0000^{* *}$ & $0.0995^{* *}$ \\
\hline Education, years & $6.56 \pm 2.87$ & $6.49 \pm 2.73$ & $6.99 \pm 3.15$ & $0.8974^{* *}$ & $0.3247^{* *}$ \\
\hline MMSE score & $19.43 \pm 2.66$ & $26.80 \pm 1.08$ & $28.47 \pm 1.23$ & $0.0000^{* *}$ & $0.0000^{* *}$ \\
\hline M@T global score & $17.61 \pm 5.71$ & $30.84 \pm 2.29$ & $44.51 \pm 3.07$ & $0.0000^{* *}$ & $0.0000 * *$ \\
\hline
\end{tabular}

Data are presented as mean \pm standard deviation unless indicated otherwise. ${ }^{*} \mathrm{p}$ value for the $\chi^{2}$ test. ** $\mathrm{p}$ value for the Student test.

Fig. 1. M@T scores according to the diagnosis in 315 subjects attended at the neurology consulting room of the 'Clínica Internacional'.

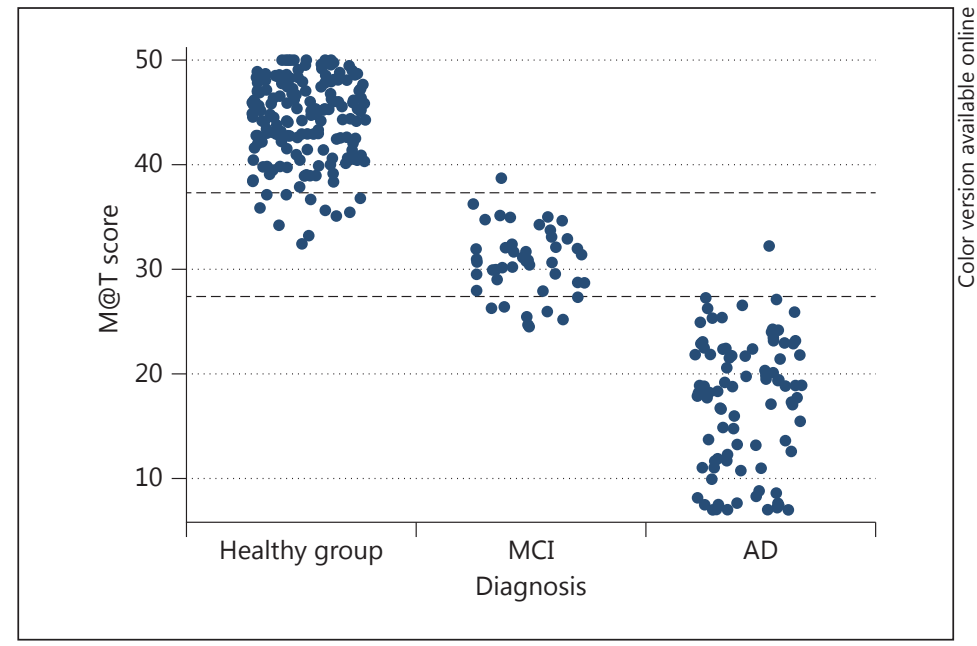

\section{Results}

Three hundred and fifteen patients were obtained from the Unit of Cognitive Impairment and Dementia Prevention of the 'Clínica Internacional' in Lima. Forty-five and ninety of them met the criteria for a-MCI and early $\mathrm{AD}$, respectively.

Our data did not show significant differences among the groups when adjusted for sex, age, and education (table 1). This is critical because age and education are considered to have an influence on cognitive performance, being evaluated by the cognitive tests applied in this study. Thus, we expect that our results are not confounded by these two factors.

According to both cognitive tests applied (MMSE and M@T), the cognitive performance of patients with early AD is significantly worse than that of patients with a-MCI (table 1 ). The scatter plot shows that the M@T had a good overall discriminability between early AD, a-MCI and CHS (fig. 1).

\section{Discriminative Validity of the M@ T}

The performance assessments of the cognitive tests are summarized in table 2. Using the $\mathrm{M} @ \mathrm{~T}$, a score of 27 provided the optimal cutoff score for discriminating between early AD 
Table 2. Cutoff points and diagnostic utility of the M@T and MMSE to discriminate between AD, MCI and CHS groups, in 315 subjects attended at the neurology consulting room of the 'Clínica Internacional'

\begin{tabular}{|c|c|c|c|c|c|c|}
\hline & \multicolumn{2}{|c|}{$\begin{array}{l}\text { Distinction between } \\
\text { patients with MCI and } \\
\text { healthy subjects }\end{array}$} & \multicolumn{2}{|c|}{$\begin{array}{l}\text { Distinction between } \\
\text { patients with AD and } \\
\text { healthy subjects }\end{array}$} & \multicolumn{2}{|c|}{$\begin{array}{l}\text { Discrimination between } \\
\text { patients with } \mathrm{AD} \text { and } \\
\text { patients with MCI }\end{array}$} \\
\hline & M@T & MMSE & $\mathrm{M} @ \mathrm{~T}$ & MMSE & M@T & MMSE \\
\hline Optimal cutoff point ${ }^{\mathrm{a}}$ & $\geq 37$ & $\geq 28$ & $\geq 27$ & $\geq 24$ & $\geq 27$ & $\geq 24$ \\
\hline Sensitivity, \% & 98.33 & 83.89 & 100.00 & 100.00 & 100.00 & 100.00 \\
\hline Specificity, \% & 97.78 & 68.89 & 98.89 & 96.67 & 98.89 & 96.67 \\
\hline Correctly classified, $\%$ & 98.22 & 80.89 & 99.63 & 98.89 & 99.26 & 97.78 \\
\hline AUC & $0.9986^{\mathrm{b}}$ & 0.8456 & 1.0000 & 1.0000 & 1.0000 & 0.9996 \\
\hline
\end{tabular}

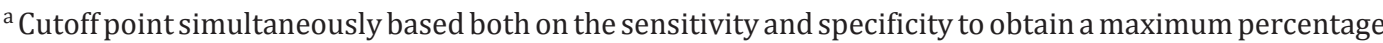
of correctly classified. ${ }^{b}$ Significant difference with regard to the MMSE, $p<0.05$. Our gold standard was the final diagnosis achieved by means of the application of the diagnostic protocol for cognitive impairment.

Fig. 2. ROC curve for the discrimination between $\mathrm{MCI}$ and $\mathrm{CHS}$ subjects by means of the application of the M@T in comparison to the MMSE in 225 subjects attended at the neurology consulting room of the 'Clínica Internacional'.

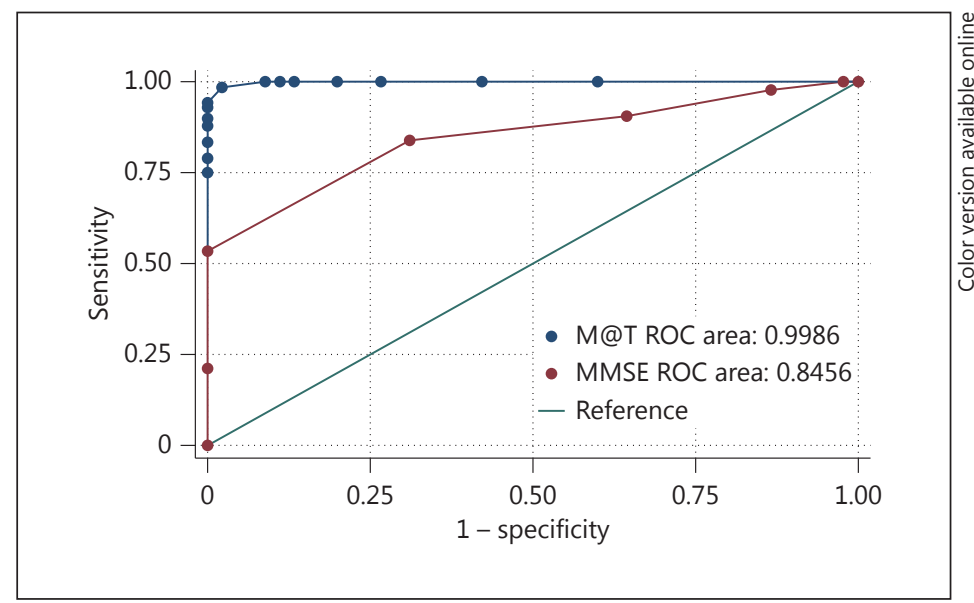

and a-MCI (sensitivity 100\%; specificity 98.9\%), whereas a score of 37 provided the optimal cutoff score for discriminating between a-MCI and CHS (sensitivity 98.3\%; specificity 97.8\%).

There were no statistical differences between the MMSE and M@T for the discrimination between early AD and a-MCI. However, the M@T was significantly better than the MMSE $\left(\mathrm{AUC}_{\mathrm{M} @ \mathrm{~T}}=0.9986\right.$ vs. $\left.\mathrm{AUC}_{\mathrm{MMSE}}=0.8456, \mathrm{p}<0.05\right)$ for the discrimination between a-MCI and CHS (fig. 2).

\section{Item Analysis of the M@T}

The results for the M@T subtests in the early AD, a-MCI and CHS groups are summarized in table 3. The only subtest with acceptable precision to discriminate between early AD and a-MCI was the orientation subtest $(\mathrm{AUC}=0.8043)$. All other items showed an AUC below 0.80, and the cued recall subtest did not show discriminatory capacity (AUC $=0.5$ ).

Otherwise, the free recall subtest was the most accurate subtest for discriminating between a-MCI and CHS (AUC = 0.9947). The encoding, orientation, and semantic subtests showed a high discriminability between a-MCI and CHS (AUC >0.80). Finally, the cued recall subtest did not show discriminatory capacity $(\mathrm{AUC}=0.5)$. 
Table 3. Neuropsychological results of the M@T subtests in 315 subjects attended at the neurology consulting room of the 'Clínica Internacional'

\begin{tabular}{|c|c|c|c|c|c|}
\hline & \multicolumn{3}{|l|}{ Groups } & \multirow{2}{*}{$\begin{array}{l}\text { AUC } \\
\text { (AD vs. MCI) }\end{array}$} & \multirow{2}{*}{$\begin{array}{l}\text { AUC } \\
\text { (MCI vs. CHS) }\end{array}$} \\
\hline & $\begin{array}{l}\mathrm{AD} \\
(\mathrm{n}=90)\end{array}$ & $\begin{array}{l}\text { MCI } \\
(n=45)\end{array}$ & $\begin{array}{l}\text { CHS } \\
(n=180)\end{array}$ & & \\
\hline $\mathrm{M} @ \mathrm{~T}_{\text {encoding }}$ & $5.76 \pm 1.98$ & $6.71 \pm 0.79$ & $8.57 \pm 0.78$ & 0.6311 & 0.9379 \\
\hline $\mathrm{M} @ \mathrm{~T}_{\text {orientation }}$ & $2.52 \pm 1.21$ & $3.84 \pm 0.74$ & $4.72 \pm 0.45$ & 0.8043 & 0.8105 \\
\hline $\mathrm{M}_{\mathrm{semantic}}$ & $6.58 \pm 2.30$ & $12.42 \pm 0.69$ & $13.59 \pm 1.04$ & 0.5000 & 0.8282 \\
\hline $\mathrm{M} @ \mathrm{~T}_{\text {free recall }}$ & $0.99 \pm 0.74$ & $2.13 \pm 1.58$ & $8.39 \pm 1.17$ & 0.7267 & 0.9947 \\
\hline $\mathrm{M} @ \mathrm{~T}_{\text {cued recall }}$ & $1.77 \pm 0.96$ & $5.73 \pm 0.78$ & $9.23 \pm 0.80$ & 0.5000 & 0.5000 \\
\hline
\end{tabular}

Data are presented as mean \pm standard deviation.

\section{Discussion}

This study showed a high precision of the M@T to discriminate between early AD, a-MCI and CHS. We found high performance values (AUC $\geq 0.99$ ), sensitivity ( $\geq 98 \%$ ), and specificity $(\geq 97 \%)$ when the M@T was applied in our sample. These findings are consistent with those previously reported by other studies $[26,31,32]$.

The cutoff score of the M@T varies according to the diagnosis suspected.When the M@T was applied using a cutoff score of 37 points, we found a sensitivity of $98.3 \%$ and a specificity of $97.8 \%$ for the diagnosis of a-MCI (AUC $=0.999$ ). This performance is higher than observed in previous studies [26, 31, 32].

Furthermore, we found a sensitivity of $100 \%$ and a specificity of $98.9 \%$ to differentiate between early AD and CHS and to differentiate between a-MCI and early AD when the M@T was applied using a cutoff score of 27 points, which is less than previously reported by Rami et al. $[26,31]$ (cutoff score $=28$ ). We used this cutoff score because it provided the best correctly classified percentage in our sample of patients.

Considering the M@T assessment (global and by subtests) for discriminating between early AD and a-MCI, the M@T AUC $C_{\text {global }}$ is higher than the M@ $\mathrm{T}$ AUC $\mathrm{C}_{\text {subtests. }}$. This suggests that the combination of subtests to discriminate between these conditions is more accurate than

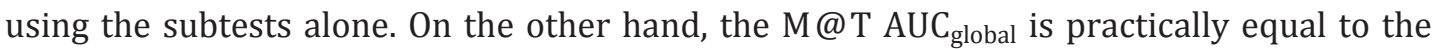
$\mathrm{M} @ \mathrm{~T} \mathrm{AUC}_{\text {recall }}$ for discriminating between a-MCI and CHS, suggesting that this subtest is as accurate as using the full test.

Furthermore, the AUC values for the cued recall subtest $(A U C=0.5)$ showed that, in our sample, this subtest was irrelevant for the discrimination between early AD and a-MCI and between a-MCI and CHS. This suggests that this subtest may be removed for the not illiterate populations, thereby reducing the application time of the M@T. This possibility should be further assessed by considering the results of the study by Carnero-Pardo et al. [32], which showed that the M@T requires a longer application time compared to other short cognitive tests (Eurotest and Phototest), being more expensive and less efficient.

The MMSE is used worldwide as a screening test for dementia, particularly at primary care centers, but its sensitivity and specificity is low for a-MCI and mild AD [24, 33]. This is related to the fact that memory impairment is often the earliest feature of $\mathrm{AD}$, and global cognitive scales present low sensitivity and specificity for detecting a-MCI and very mild AD. Indeed, in our sample, the MMSE showed a low performance for discriminating between early $\mathrm{AD}, \mathrm{a}-\mathrm{MCI}$ and CHS. 
The present study has the following limitations. We only took into consideration the analysis of the M@T by subtests. However, a closer analysis (by items) could evaluate whether a combination of less items is as or more accurate than the application of all items. Otherwise, the $\mathrm{M} @ \mathrm{~T}$ was designed to screen a-MCI and typical AD, and it evaluates temporal orientation and different types of memory (episodic, textual, and semantic). Therefore, its utility in atypical $\mathrm{AD}$ presentations or other dementias (in which language or frontal functions may be the earliest manifestation) is uncertain.

In conclusion, the $\mathrm{M} @ \mathrm{~T}$ is a reliable, brief, and simple test with high precision for discriminating between early $\mathrm{AD}$, a-MCI and CHS. Thus, it is a valuable tool for easy and early cognitive impairment detection at the primary care setting.

\section{Disclosure Statement}

The authors declare that they have no conflicts of interest.

\section{References}

1 Custodio N, García A, Montesinos R, Escobar J, Bendezú L: Prevalencia de demencia en una población urbana de Lima-Perú: un estudio puerta a puerta. An Fac Med 2008;69:233-238.

$\longrightarrow 2$ Ferri CP, Prince M, Brayne C, Brodaty H, Fratiglioni L, Ganguli M, et al: Global prevalence of dementia: a Delphi consensus study. Lancet 2005;366:2112-2117.

-3 Herrera E Jr, Caramelli P, Silveira ASB, Nitrini R: Epidemiologic survey of dementia in a community-dwelling Brazilian Population. Alzheimer Dis Assoc Disord 2002;16:103-108.

4 Kalaria RN, Maestre GE, Arizaga R, Friedland RP, Galasko D, Hall K, et al: Alzheimer's disease and vascular dementia in developing countries: prevalence, management, and risk factors. Lancet Neurol 2008;7:812-826.

-5 Llibre JJ, Guerra MA, Pérez-Cruz H, Bayarre H, Fernández-Ramírez S, González-Rodríguez M, et al: Dementia syndrome and risk factors in adults older than 60 years old residing in Habana. Rev Neurol 1999;29:908-911.

-6 Nitrini R, Bottino CMC, Albala C, Custodio Capuñay NS, Ketzoian C, Llibre Rodriguez JJ, et al: Prevalence of dementia in Latin America: a collaborative study of population-based cohorts. Int Psychogeriatr 2009;21: 622-630.

7 World Health Organization: Dementia: a public health priority. 2012. http://www.who.int/mental_health/ publications/dementia_report_2012/en/index.html (accessed December 4, 2012).

-8 Mías CD, Sassi M, Masih ME, Querejeta A, Krawchik R: Mild cognitive impairment: a prevalence and sociodemographic factors study in the city of Córdoba, Argentina. Rev Neurol 2007;44:733-738.

$\$ 9$ Henao-Arboleda E, Aguirre-Acevedo DC, Muñoz C, Pineda DA, Lopera F: Prevalence of mild cognitive impairment, amnestic-type, in a Colombian population. Rev Neurol 2008;46:709-713.

10 Petersen RC: Mild cognitive impairment as a diagnostic entity. J Intern Med 2004;256:183-194.

-11 Petersen RC, Stevens JC, Ganguli M, Tangalos EG, Cummings JL, DeKosky ST: Practice parameter: early detection of dementia: mild cognitive impairment (an evidence-based review). Report of the Quality Standards Subcommittee of the American Academy of Neurology. Neurology 2001;56:1133-1142.

$\checkmark 12$ Ritchie K, Artero S, Touchon J: Classification criteria for mild cognitive impairment: a population-based validation study. Neurology 2001;56:37-42.

13 Markesbery WR, Schmitt FA, Kryscio RJ, Davis DG, Smith CD, Wekstein DR: Neuropathologic substrate of mild cognitive impairment. Arch Neurol 2006;63:38-46.

14 Morris JC: Mild cognitive impairment and preclinical Alzheimer's disease. Geriatrics 2005;(suppl):9-14.

15 Folstein MF, Folstein SE, McHugh PR: 'Mini-mental state'. A practical method for grading the cognitive state of patients for the clinician. J Psychiatr Res 1975;12:189-198.

16 Buschke H, Kuslansky G, Katz M, Stewart WF, Sliwinski MJ, Eckholdt HM, et al: Screening for dementia with the memory impairment screen. Neurology 1999;52:231-238.

17 Roth M, Tym E, Mountjoy CQ, Huppert FA, Hendrie H, Verma S, et al: CAMDEX. A standardised instrument for the diagnosis of mental disorder in the elderly with special reference to the early detection of dementia. Br J Psychiatry 1986;149:698-709.

18 Hendrie HC, Hall KS, Brittain HM, Austrom MG, Farlow M, Parker J, et al: The CAMDEX: a standardized instrument for the diagnosis of mental disorder in the elderly: a replication with a US sample. J Am Geriatr Soc 1988;36:402-408.

19 Huppert FA, Brayne C, Gill C, Paykel ES, Beardsall L: CAMCOG - a concise neuropsychological test to assist dementia diagnosis: socio-demographic determinants in an elderly population sample. Br J Clin Psychol $\mathrm{Br}$ Psychol Soc 1995;34:529-541. 
20 Neri M, Roth M, De Vreese LP, Rubichi S, Finelli C, Bolzani R, et al: The validity of informant reports in assessing the severity of dementia: evidence from the CAMDEX interview. Dement Geriatr Cogn Disord 1998;9:56-62.

21 Solomon PR, Hirschoff A, Kelly B, Relin M, Brush M, DeVeaux RD, et al: A 7 minute neurocognitive screening battery highly sensitive to Alzheimer's disease. Arch Neurol 1998;55:349-355.

-22 Solomon PR, Brush M, Calvo V, Adams F, DeVeaux RD, Pendlebury WW, et al: Identifying dementia in the primary care practice. Int Psychogeriatr 2000;12:483-493.

23 Tang-Wai DF, Knopman DS, Geda YE, Edland SD, Smith GE, Ivnik RJ, et al: Comparison of the short test of mental status and the mini-mental state examination in mild cognitive impairment. Arch Neurol 2003;60: 1777-1781.

24 Tierney MC, Szalai JP, Dunn E, Geslani D, McDowell I: Prediction of probable Alzheimer disease in patients with symptoms suggestive of memory impairment. Value of the Mini-Mental State Examination. Arch Fam Med 2000;9:527-532.

25 Gifford DR, Cummings JL: Evaluating dementia screening tests: methodologic standards to rate their performance. Neurology 1999;52:224-227.

26 Rami L, Molinuevo JL, Sanchez-Valle R, Bosch B, Villar A: Screening for amnestic mild cognitive impairment and early Alzheimer's disease with M@T (Memory Alteration Test) in the primary care population. Int J Geriatr Psychiatry 2007;22:294-304.

-27 Petersen RC, Doody R, Kurz A, Mohs RC, Morris JC, Rabins PV, et al: Current concepts in mild cognitive impairment. Arch Neurol 2001;58:1985-1992.

28 McKhann G, Drachman D, Folstein M, Katzman R, Price D, Stadlan EM: Clinical diagnosis of Alzheimer's disease: report of the NINCDS-ADRDA Work Group under the auspices of Department of Health and Human Services Task Force on Alzheimer's Disease. Neurology 1984;34:939-944.

29 Pfeffer RI, Kurosaki TT, Harrah CH Jr, Chance JM, Filos S: Measurement of functional activities in older adults in the community. J Gerontol 1982;37:323-329.

30 Morris JC, Mohs RC, Rogers H, Fillenbaum G, Heyman A: Consortium to establish a registry for Alzheimer's disease (CERAD) clinical and neuropsychological assessment of Alzheimer's disease. Psychopharmacol Bull 1988;24:641-652.

31 Rami L, Bosch B, Sanchez-Valle R, Molinuevo JL: The memory alteration test (M@T) discriminates between subjective memory complaints, mild cognitive impairment and Alzheimer's disease. Arch Gerontol Geriatr 2010;50:171-174.

32 Carnero-Pardo C, Espejo-Martínez B, López-Alcalde S, Espinosa-García M, Sáez-Zea C, Hernández-Torres E, et al: Diagnostic accuracy, effectiveness and cost for cognitive impairment and dementia screening of three short cognitive tests applicable to illiterates. PloS One 2011;6:e27069.

33 Tombaugh TN, McIntyre NJ: The Mini-Mental State Examination: a comprehensive review. J Am Geriatr Soc 1992;40:922-935. 